\title{
Development of a smart city information system
}

\author{
Justas Streimikis ${ }^{1,2 *}$, Liudmila Kortenko ${ }^{3}$, Marina Panova ${ }^{3}$, and Mikhail Voronov ${ }^{3}$ \\ ${ }^{1}$ Institute of Economics and Rural Development, Lithuanian Centre for Social Sciences, A. Vivulskio \\ g. 4A-13, LT-03220 Vilnius, Lithuania \\ ${ }^{2}$ University of Economics and Human Science in Warsaw, Faculty of Management and Finances, \\ Okopowa 59, 01-043Warsaw, Poland \\ ${ }^{3}$ Ural State University of Economics, 62 8-Marta Str., Ekaterinburg, 620144, Russian Federation
}

\begin{abstract}
This paper is centred around the development of a smart city information system. Smart cities use the framework of information and communications technologies to create, deploy and promote practices that address urban challenges and create, connect and enable sustainable infrastructure. This definition focuses on network deployment, transport, ICT investment, human and social capital to support sustainable community goals and quality of life by involving users of certain technologies and community-based applications in social participation. In this paper, we show that a multi-disciplinary approach is needed to address these issues, combining expertise from distributed systems, software and services engineering, network and data management and processing, crowdsourcing, sensor and update methods, social computing, as well as the collective intelligence.
\end{abstract}

Keywords: sustainable infrastructure, smart city, information technology.

\section{Introduction}

Smart cities use a variety of software, user interfaces, communications networks and the Internet of Things (IoT) to provide connected solutions to the public. A smart city is a concept for integrating information and communications technology (ICT) with various physical devices connected to IoT (Internet of Things) networks in order to optimise the efficiency of city operations and services for connected citizens [1-3]. Smart cities use ICT to improve efficiency of operations, share information with the public and provide better government services for citizens' well-being. ICT can be used to improve the quality, performance and interactivity of urban services, reduce costs and resource consumption and improve communication between citizens and government $[4,5]$. A smart city is a municipality that uses information and communications technology (ICT) to increase its operational efficiency, share information with the public and ensure a better quality of government services and citizens' well-being. The main objective of a smart city should be to optimise city functions, promote economic growth and improve the citizens' quality of life through use of smart technologies and data analysis. In general, a smart city improves governance, improves the

\footnotetext{
*Corresponding author: justas.streimikis@gmail.com
} 
economic image of the city, improves the quality of life of its citizens and contributes to the creation of environmentally friendly and sustainable infrastructure [6].

The value attached to smart cities depends on whether or not they choose technology and how much technology they have. This leads to highlighting several common features, characteristics and components that can be specified from the perspective of an intelligent city. These include the intensive use of ICT as the next generation of information technology, the integration of the city's physical and social components, the use of ICT to implement advanced monitoring and control tools and applications to increase efficiency and quality and the improvement of infrastructure to support a better quality of life and sustainability. Moreover, there is huge potential to use big data to address many of the problems of a smart city by the use of analytics to improve deeper insights and better decision-making practices. The use of technologies based on the Internet of Things (IoT) and the integration of an online population into a new system will make cities as new and developing smart cities' function $[7,8]$. Politicians and urban planners are laying the groundwork to use technologies to meet residents' needs, provide greater efficiency and provide services to create a smart city. This requires intelligent IoT solutions to optimize infrastructure and governments to involve citizens in the management of services. Playing with new technologies will provide cities with robust solutions that benefit citizens $[9,10]$.

Initiatives such as the Smart City Information Systems (SCI) brings together project developers, cities, research institutions, industry experts and citizens from all across Europe. Cities want to integrate smart systems into their industrial, infrastructural, educational and social activities. Why we need smart cities The main goal of a smart city is to create an urban environment that offers a better quality of life to its inhabitants and generates macroeconomic growth $[11,12]$. City leaders should not only raise awareness about the benefits of smart city technology but also implement and promote the use of open and democratized data for their citizens.

Smart city start-ups are over 1,200 companies that are developing solutions and services for future cities that are revolutionizing sectors such as public safety, transportation and utility management [13]. Several areas of cities are becoming smarter, from traffic management to water management, and different companies are working on different components. The information is linked to the urban infrastructure, citizen applications, Information gathering technologies, external databases and other data repositories and connections for communication with the information received [14]. The integration of the information is done as far as possible by the existing vendors of infrastructure and citizen applications and open data from external databases, but in other ways. Sensors, networks and applications gather data on energy consumption, traffic, pollution and other issues which can be analysed and used to correct and predict usage patterns. Sensor data from citizens and objects can be processed in real time using real-time systems [15]. Using this technology, one can detect what is happening in the city as it evolves to provide a better quality of life. This implies that new electronic services and technologies for smart urban development should emphasize the importance of user-oriented and city-specific applications in order to identify the appropriate channels for successful delivery of services to strengthen the development potential of communities [16]. The latter is crucial, as customer profiling and sharing with citizens of services can lead to sustainable and effective e-services that offer high levels of citizen satisfaction and a high deforestation potential. The design of the architecture should make it possible to remedy the shortcomings of the current platforms. Data flows, data exchange and network components in the IoT are subject to effective risk management, and assessing and responding to threats to smart cities is challenging due to technical sophistication and standard immaturity $[17,18]$.

Giving high priority to strong security systems is crucial for smart cities, as these vulnerabilities can expose them to all kinds of catastrophic and costly events. A study by 
Abosaq [19] looked at the privacy problems of smart cities, including authentication, access control, confidentiality, trust, data security policies and implementation of secure middleware. The study suggested that data protection can be achieved through faster I/O and FIDO authentication processes (FIDO Alliance 2019), device-to-network and device-tocloud authentication and that data protection should be seen as an integral part of Smart City infrastructure.

\section{Cities as a symbol of the high-level form of human society}

Karl Marx provided a model for understanding the evolution of any kind of society. He argued that the evolution of the society from primitive to progressive was not a result of the way people thought, as Comte suggested, but of power struggles between epochs among various social classes over control of the property [20]. Group theorists use systems theory to view civilization as a complex system, a framework in which groups of objects are analysed and work together to achieve results. Huntington defined civilization as: "a highly cultural group of people with a broad degree of cultural identity, people who, in short, distinguish people from other species" [21]. Organization of complex social systems and a great organization. It can be seen as a network of cities formed from pre-urban cultures and is defined by the economic, political, military, diplomatic, social and cultural interactions within those cultures.

Civilization is a complex society characterized by urban development, social stratification, forms of government, and symbolic communication systems such as writing. Many civilizations have a large cultural sphere that encompasses many nations and regions. As a civilization grows, cities become larger and more distinct from rural and agricultural areas. Trade, conflict and exploration are all present, while civilizations grow and remain stable for long periods. As great empires expand in to such large regions, language, culture, and customs dilute the identity of the inhabitants of the empires [22, 23]. This view of excessive religiosity of ancient peoples contradicts the findings of comparative anthropology and can be seen as a trigger for understanding early civilizations. Applied to urban planning and cities, this view leads to an exaggerated emphasis on religious and symbolic aspects of urban design. There are several additional factors hampering the analysis of the high-ranking importance of ancient cities. There is a long tradition of overemphasizing the role of religion in ancient societies. Compared to the earlier era of time and comfort in which all parts of the population had time and comfort to engage in contemplative and reflective activities such as music, poetry and philosophy, this was described as the beginning of civilization and the development of leisure and art. The first people in the region to reach the complexity that historians today call civilization. They had done this around $3100 \mathrm{BC}$ and developed a civilization in which city-states formed over the next 7 centuries [24]. Before them, several independent city states existed simultaneously, some of which were in fierce competition with each other. Technological developments in the fields of transport and communication mark a new epoch in the history of humanity, emphasizing the role of the city as a dominant element of our civilization and extending the urban way of life beyond the boundaries of a city [25-27].

The dominance of cities, particularly large cities, is seen as a consequence of the concentration of cities around industrial, commercial, financial and administrative facilities, transport and communication lines activities, cultural and leisure facilities such as presses, radio stations, theatres, libraries, museums, concert halls, operas, hospitals, universities, research and publishing centres, professional associations and religious and social institutions. Cities and countries are regarded as two points of reference, one above the other, and human settlements tend to be arranged as they are now. The last element that is crucial for the development of civilisation is the division of people into classes [28]. In the ancient 
civilizations, there were four great kinds of social classes. Scholars and political leaders constituted the most powerful social class. Several thousand other people lived in the valley, producing agricultural surpluses to feed the towns and municipalities, growing cattle for their sheep, sorghum and millet, and processing iron. They developed a unique tropical agricultural system that spread across the continent and became the basis of a complex society trading. This extraordinary story is at the heart of a thriving civilisation [29, 30]. People started farming because a small part of our planet was fortunate enough to have the best plants and animals in the world, which gave a group of people in history a unique advantage. Cities are growing up, mines and railways emerging, and Europeans building on the European model. At the same time, the most important centres of contemporary cultural industries are entangled in the stubborn process of globalization. We would argue that the economic basis of this trend lies in part in the structural characteristics of image-producing industries, characterized by their modularized networks and production structures and a strong tendency to geographical agglomeration.

\section{Smart city information system based on the IoT \& cloud computing}

Smart homes are IoT-enabled appliances, air conditioning and heating systems, televisions, audio and video streaming devices and security systems that communicate to each other to provide the best comfort and security while reducing energy consumption [31]. The IoT is a network of connected devices such as cars, sensors and household devices that communicate and exchange data. This communication takes place via IoT-based central control units that use the Internet. The data collected and delivered by IoT sensors and devices is stored on cloud servers. Resource use and other devices play an important role in analysing, managing and managing the resources of an IoT smart city [32]. Connecting IoT sensors and devices with the use of data analytics (DA) facilitates the convergence of physical and digital urban elements to improve efficiency of public and private sectors, provide economic benefits and improve citizens' lives. The Smart City ecosystem collects data by intelligent sensors at the edge can be transformed into a cloud fog for processing, managing, storing, interpreting and operating various IoT applications. The diverse sectors of smart cities have recently expanded the possibilities of smart technologies in action. Smart urban technologies have led to efficiency gains in urban manufacturing and agriculture, including jobs creation, energy efficiency, space management and fresher products for consumers [33, 34].

IoT research is revolutionising smart city services. Proper use of resources and other devices plays an important role in the study, management and management of IoT resources in a smart city. Cities around the world are turning to this technology and advanced networks to help them overcome resource scarcity. With $65 \%$ of US Internet users comfortable with the idea of living in a smart city, the adoption of this technology in the coming years will continue to grow [35]. As populations and urbanization increase, many cities will turn to the Internet of Things (IoT) and advanced networks in the coming years to help themselves cope with resource scarcity. Smart cities offer solutions for rapid urbanization, exploding populations, scarce resources, congestion of traffic and energy management through the effective and integrated use of information and communication technologies. The design, integration and implementation of smart cities is recognised as a means to optimise limited resources and improve people's quality of life. We outline how smart cities offer their inhabitants an efficient and high-quality lifestyle and what methods they use to achieve these goals [36].

Thence, it is interesting to examine the role of emerging technologies in smart city solutions. It examines various topics including traffic management, air quality management, public safety solutions, smart parking, smart lighting and smart waste collection. In line with 
Smart Cities use cases, the proposed study introduces an Analytics Network Process (ANP) to evaluate Smart Cities. The Smart City energy system's aspect is crucial for the overall security and privacy of the infrastructure as third parties can connect to the grid to monitor usage patterns and predict consumer behaviour [37]. Wireless network technology focuses on the nature of many systems that supply and control the city with heat and light, exposing vulnerabilities in network security. Security, privacy and health services. The concept of smart cities is a key factor in the overall minimum disclosure of data and information security infrastructure [38]. Data protection is a key issue for smart cities and one that is linked to a minimal understanding of privacy by local governments and businesses when collecting and processing personal data. Other legal issues such as jurisdiction and governance as well as the handling and consent of data in smart cities will also be examined. In order to support the Internet of Things and cloud computing [39, 40].

City systems are based on these technologies. Traditional urban systems, such as those handed down from antiquity, are inefficient and cumbersome, because information systems are not shared and interconnected. It is obvious that some sectors (smart cities, smart energy, smart vehicles) based on IoT projects have a larger market share compared to others. It can be seen that the American continent contributes more to health care and smart supply chain projects, while the European continent contributes more to smart urban projects [41]. The Internet of Things (IoT) is a platform for global networking and the integration of sensors, actuators, RFID, Bluetooth and other digital devices. It consists of integrated components, services, data networks and sensors. The Internet of Things (IoT) is an important driver of smart cities by facilitating communication between a large number of devices. IoT connectivity and interoperability will help build a smart city around the world.

\section{Urban computing for intelligently improving the lives of citizen}

One can see that urban computing for intelligently improving human lives is important in order to create a coherent framework that includes all the approaches that are capable of dealing with such issues. The results generated by our framework will be useful to a variety of applications including urban planning, site selection, business and social recommendations. Specific experiments will be carried out to validate solutions and proof of concept, which will be repeated as often as possible with real case studies and pilot projects. Urban computing is an interdisciplinary area that combines information and communication technologies, advanced management of large amounts of data, and diverse methods of data analysis to propose solutions to urban problems. Urban computing helps us understand the nature of urban phenomena and predict the future of cities. It combines discreet and ubiquitous sensor technology with advanced data management and analysis models and novel visualization techniques to create win-win solutions to improve the urban environment, human life and the quality of urban operations and systems. Urban Computing combines urban sensors, data management and data analytics services to provide recurring processes for the unobtrusive and continuous improvement of people's lives, urban operations, systems and environments $[42,43]$. Smart cities use information and communication technologies (ICT) to increase operational efficiency, share information with the public and ensure a better quality of public services for citizens' well-being. Smart cities' main objective is to optimise urban functions, promote economic growth and improve the quality of life of citizens through the use of smart technologies and data analysis. Connected devices that communicate and exchange data include vehicles, household appliances and street sensors. The collected data by these devices is stored on cloud servers that can improve both the efficiency of the public and private sectors with economic benefits and improvements in citizens' lives. The data must be available in real time and with reliable access to ensure that it fulfils its functions and monitors different parts of the smart city infrastructure [44]. With regard to this, one can 
define an intelligent city as an urban area that functions as a robust system - a system of economic, social, environmental and governmental activities based on sustainable practices driven by AI technologies that can help us achieve social well-being and other desired outcomes for the future of humans and non-humans. The modern city is a complex and pluriform ecosystem that requires thorough scientific treatment and sustained policy management. The city is more than a collection of places and people - places need to be reinvented and reinvented by the people who occupy them [45]. Some scientists see AI as an opportunity to drive smart cities and intelligence of cities while others see AI generating a whole new brand in our cities as AI applications become mainstream [46]. In the age of smart cities, urban areas are adapted to smart technologies, including sensors and networks. With the increasingly sophisticated capabilities of artificial intelligence, we see the potential for dramatic changes in our cities and societies. The explosion in data growth is due to a number of key technologies in ICT and various forms of ubiquitous computing, and these technologies are increasingly embedded in the fabric of modern and futuristic cities. At this point, much of the ICT investment is directed toward technology giants such as Google, IBM, Oracle, Microsoft, SAP and Cisco to develop novel computing models that improve existing practices for different purposes in terms of storage, processing, analysis, management, modelling, simulation, evaluation, big data visualization, deployment and analytical results. Big data analytics is a prerequisite for the realization of new applications and services that promise ICT vision and ubiquitous computing as determinants, enablers and powerful drivers of such cities.

Many smart applications affect our lifestyles, but many applications remain outside the digital world. In recent years, the importance of scale analysis and hierarchical modelling on the hierarchical organization of complex urban systems has led to a broad interest in systemic urban studies. New approaches to understanding and managing urban dynamics, complex policy issues, functional flow networks, bilateral and multi-level interconnections, coordination of efforts at the sub-functional level of the urban spatial economy in combination with intelligent transformations from big data to intelligent data management represent newer concepts of collective intelligence. An intelligent city is defined as an intelligent environment that is embedded in ICT and aims to create interactive spaces that bring computation into the physical world. From the perspective of smart cities, smart space refers to the physical environment in which ICT sensor systems disappear when embedded in physical objects and environments in which we live, work and travel. Smart cities are communities, clusters or regions defined as multi-layered territorial innovation systems that bring together knowledge-intensive activities, institutions, cooperation, learning and innovation in digital spaces of communication and interaction to increase the city's problemsolving capacity. Cisco today unveiled its holistic design for smart urbanization, a global initiative designed to help cities around the world utilize networks as the next tool to integrate urban management for better quality of life for citizens and economic development.

\section{Conclusions}

All in all, it is apparent that smart city information systems can track citizens, provide emergency services, offer preventive measures, analyse citizens' data, use it for better research and practice, create sustainable development through better use of food and energy, manage waste and inventory management in all possible ways. The potential to improve various aspects of the public service system and quality of life while reducing costs is driving demand for smart cities. By taking a step forward, we can not only improve the way we interact with our general environment, but also the way cities interact with us to ensure that we get the best quality options while wasting fewer resources. 
As population and urbanization in the coming years increase, many cities will turn to technology and advanced networks to help them face resource scarcity. In particular, cities are turning to a part of the Internet of Things (IoT), the so-called Smart City solutions. Smart cities use IoT devices such as connected sensors and light meters to collect and analyse data. Smart cities use data to improve infrastructure, public utilities, and more. Intelligent urban infrastructure includes various factors such as information and communication technologies, Internet of Things, public-private partnerships and social and human capital. The Internet of Things connects electronic devices other than computers and smartphones to the Internet of Things to efficiently monitor and manage daily activities. These are kitchen appliances, buildings, vehicles, health appliances, lighting, waste management, security systems and energy management. The beneficiaries of these devices are consumers, governments and private companies. Internet of Things has an enduring effect on our cities. It does not begin and end with urban buildings, morning commute and public parks, all equipped with the technology of the Internet of Things. When most of the Internet users are comfortable with the idea of living in a smart city, adoption of the technology will continue to increase in the coming years.

Cities around the world are turning to technology and advanced networks to help them overcome resource scarcity. Data-driven research gives one's business insights into the latest innovations, market trends and your competitors. Novel applications of IoT, from public health monitoring to global supply chain integration, offer huge benefits and draw attention to significant governance gaps around these technologies. Worldwide, urban populations are increasing and cities are struggling to keep pace. In addition, COVID-19 and the global economic crisis are forcing cities to rethink and recalibrate long-term strategic plans and economic development strategies. The silent force that could revolutionize the world is the technology that can be used to manage rapid urbanization and create smarter cities. The Internet of Things, created as part of the smart technology movement, enables various objects and entities to communicate via the Internet to each other. The creation of a network of objects that enable intelligent interactions is the door to a broad range of technological innovations that can help improve public transport, generate accurate traffic reports and provide real-time energy consumption data. Raconteur examines in today's infographic how the IoT is becoming a critical component in creating more efficient, sustainable and resilient cities and shows the growing impact it has on people around the world.

The range of Smart City applications is diverse, but the similarities lie in the approach to implementation. The following six-step implementation model shows what steps need to be taken to create an efficient and scalable IoT architecture for smart cities. Just as smartphones bring the world to our fingertips, smart cities have state-of-the-art technology to improve quality of life throughout the city. Smart city applications can affect various levels of quality of life in the dimensions of security, convenience, health, environmental quality, social connectivity, civic participation, jobs and cost of living. There are many other benefits of smart cities and we are seeing new applications being explored. Sensors and technologies that provide real-time data can influence personal comfort at the micro level, sustainability, and clean energy at the macro level. The list of smart technologies to be integrated into cities in the future include smart sprinkler systems that conserve water by monitoring the optimal level of hydration required in urban parks and city parks, smart parking meters and prepaid energy management. The whole city is designed to tackle congestion and parking problems and make our way of life greener. Every city has a different strategy, and citizens are proving that cities are an important asset. The growing population creates the need to rediscover the way we live and create better environments that are smarter, more efficient, and more sustainable. Continued migration to urban areas is putting more pressure on public services and urban planning. 
As a result, cities are implementing technology and data-driven solutions to reduce or increase the burden of population growth. Technology can lead to a wide range of transformative effects if cities are willing to embrace it. Building a smart economy and governance can improve infrastructure, increase security, reduce energy consumption and costs, and reduce environmental impacts. Moreover, the most obvious area where IoT is already being implemented to improve security in urban areas is video surveillance. This allows police to monitor a live feed of the entire city and rely on AI systems to detect and report and target crime.

\section{References}

1. Y. Mehmood, F. Ahmad, I. Yaqoob, A. Adnane, M. Imran, S. Guizani, IEEE Communications Magazine, 55(9), 16-24 (2017)

2. S. Talari, M. Shafie-Khah, P. Siano, V. Loia, A. Tommasetti, J. Catalão, Energies, 10(4), 421 (2017)

3. W. Strielkowski, T. Veinbender, M. Tvaronavičienè, N. Lace, Economic ResearchEkonomska Istraživanja, 33(1), 788-803 (2020)

4. E. Ismagilova, L. Hughes, Y. Dwivedi, K. Raman, International Journal of Information Management, 47, 88-100 (2019)

5. B. Silva, M. Khan, K. Han, Sustainable Cities and Society, 38, 697-713 (2018)

6. J. De Guimarães, E. Severo, L. Júnior, W. Da Costa, F. Salmoria, Journal of Cleaner Production, 253, 119926 (2020)

7. F. Provost, T. Fawcett, Big data, 1(1), 51-59 (2013)

8. M. Mahdavinejad, M. Rezvan, M. Barekatain, P. Adibi, P. Barnaghi, A. Sheth, Digital Communications and Networks, 4(3), 161-175 (2018)

9. S. Tan, A. Taeihagh, Sustainability, 12(3), 899 (2020)

10. S. Bibri, Sustainable Cities and Society, 38, 230-253 (2018)

11. L. Zhao, D. Zhang, T. Zhu, T. Zhang, F. Wu, Transformations in Business and Economics, 20(1), 69-92 (2021)

12. Y. Lim, J. Edelenbos, A. Gianoli, Cities, 95, 102397 (2019)

13. CBInsights, https://www.cbinsights.com/research/what-are-smart-cities (2021)

14. M. Ottaviano, M. Beltrán-Jaunsarás, J. Teriús-Padrón, R. García-Betances, S. GonzálezMartínez, G. Cea, M. Arredondo Waldmeyer, Sensors, 19(13), 2940 (2019)

15. G. Rausser, W. Strielkowski, D. Štreimikienè, Energy \& Environment, 29(1), 131-146 (2018)

16. N. Komninos, Smart Cities and Connected Intelligence: Platforms, ecosystems and network effects (2019)

17. I. Makhdoom, M. Abolhasan, J. Lipman, R. Liu, W. Ni, IEEE Communications Surveys \& Tutorials, 21(2), 1636-1675 (2018)

18. C. Wheelus, X. Zhu, IoT, 1(2), 259-285 (2020)

19. N. Abosaq, International Journal of Advanced Computer Science and Applications, 10(2), 177-185 (2019)

20. F. Boldizzoni, Foretelling the End of Capitalism: Intellectual Misadventures Since Karl Marx (2020)

21. F. Rizvi, Educational Philosophy and Theory, 43(3), 225-235 (2011) 
22. D. LePoire, Journal of Big History, 3(2), 1-16 (2019)

23. M. Kirby, History of Civilizations (2018)

24. T. Eskelson, Journal of Education and Learning, 9(2), 29-47 (2020)

25. R. Macrorie, S. Marvin, A. While, Urban Geography, 42(2), 197-217 (2021)

26. A. Chiabai, S. Platt, W. Strielkowski. Tourism Economics, 20(2), 263-277 (2014)

27. S. Bibri, Smart sustainable cities of the future (2018)

28. J. Zhang, Study of Ecological Engineering of Human Settlements (2020)

29. D. Montgomery, Dirt: The erosion of civilizations (2021)

30. M. Hansen, R. Svarverud, Global Environmental Change, 53, 195-203 (2018)

31. S. Kumar, P. Tiwari, M. Zymbler, Journal of Big Data, 6(1), 1-21 (2019)

32. M. Sadeeq, S. Zeebaree, Journal of Applied Science and Technology Trends, 2(2), 59$71(2021)$

33. H. Chegini, R. Naha, A. Mahanti, P. Thulasiraman, IoT, 2(1), 92-118 (2021)

34. M. Sokolova, H. Mohelska, Transformations in Business and Economics, 19(3), 603617

35. M. Agbali, C. Trillo, I. Ibrahim, Y. Arayici, T. Fernando, Smart Cities, 2(2), 307-327 (2019)

36. K. Kuru, D. Ansell, IEEE Access, 8, 18615-18644 (2020)

37. I. Wang, H. Ninomiya, B. Gussen, Sharing Cities (2020)

38. H. Habibzadeh, B. Nussbaum, F. Anjomshoa, B. Kantarci, T. Soyata, Sustainable Cities and Society, 50, 101660 (2019)

39. H. Lim, A. Taeihagh, Energies, 11(5), 1062 (2018)

40. L. Vandercruysse, C. Buts, M. Dooms, Cities, 104, 102731 (2020)

41. P. Gupta, S. Chauhan, M. Jaiswal, Information Systems Frontiers, 21(3), 661-685 (2019)

42. W. Qi, Z. Shen, Production and Operations Management, 28(2), 393-406 (2019)

43. S. Bibri, Computational Urban Science, 1(1), 1-32 (2021)

44. J. Cha, S. Singh, T. Kim, J. Park, Journal of Information Security and Applications, 57, 102686 (2021)

45. K. Kourtit, Asia-Pacific Journal of Regional Science, 5(1), 191-222 (2021)

46. Z. Allam, Z. Dhunny, Cities, 89, 80-91 (2019) 